\section{NON-CONTRAST MRI FOR ASSESSMENT OF THORACIC} AORTA DIMENSION

${ }^{1}$ Mehak Gupta*, ${ }^{2}$ Hannah Clarke, ${ }^{3}$ Oscar Hargreaves, ${ }^{1}$ Tom Ingram, ${ }^{2}$ Vijay Pakala, ${ }^{2}$ Eveline Lee, ${ }^{4}$ Jemiliat Otun. ${ }^{1}$ Shrewsbury and Telford Trust; ${ }^{2}$ Shrewsbury and Telford NHS Trust, Telford, UK; ${ }^{3}$ University of Birmingham; ${ }^{4}$ Princess Royal Hospital, Telford, UK

10.1136/heartjnl-2021-BCS.174

Introduction Multi-modality imaging plays a significant role in evaluating and interval monitoring of patients with aortopathies. Echocardiogram is the first screening test followed by Computerised Tomography (CT) and/or Magnetic Resonance Imaging (MRI). Most patients require repeated scans at interval. Both CT and MRI require contrast administration and furthermore, radiation exposure in CT. Locally, we have c adopted surveillance scanning with non-contrast MR to overcome the above limitations. This is not widely practised.

Aim The aim of the study is to compare inter-modality agreement between CT (gold standard) and non-contrast MRI measurements of ascending aortic dimensions.

Methods 126 consecutive patients underwent non-contrast MRI thoracic aorta our hospitals between 2017 and 2021. Thirty-eight patients (61\% males, age $61 \pm 14$ years) have had both CT and MRI. A retrospective analysis was conducted to assess the inter-modality agreement of ascending aorta measurements. Statistical analysis was done using $\mathrm{R}$ programme ( $\mathrm{R}$ studio). A Bland-Altman graph was used to assess inter-modality agreement of ascending aorta measurements. Differences in measurements of the two modalities were reported as mean and $95 \%$ confidence interval.

Results There is good linear correlation (Pearson's $\mathrm{R}=0.86$, $\mathrm{p}<0.05$ ) between CT and MRI measurements. Mean difference between CT and MRI measurements was $2.39 \mathrm{~mm}$, 95\% confidence interval $6.5 \mathrm{~mm}$ to $8.4 \mathrm{~mm}$, see figure 1 .
Conclusion There is good inter-modality agreement of ascending aorta measurements between CT non contrast MRI in our experience. Non contrast MRI has the advantage of requiring no radiation and no need for contrast. This is desirable particularly in young patients requiring long term surveillance. Conflict of Interest Nil

\section{IMPLEMENTING AN ENDOCARDITIS MULTIDISCIPLINARY TEAM AND WEEKLY MEETING IN A NON-SURGICAL CENTRE: A HEALTHCARE MODEL TO MAKE THE COMPLEX MORE SIMPLE}

${ }^{1}$ Louise Brown, ${ }^{1}$ Krithika Loganath, ${ }^{1}$ Khalda Halim, ${ }^{1}$ Georgios Mangouretsios, ${ }^{1}$ Mihye Lee, ${ }^{2}$ Geoff Tsang, 'Christopher Steadman, 'Peter O'Kane. 'University Hospitals Dorset, Bournemouth, UK; ${ }^{2}$ University Hospital Southampton

\subsection{6/heartjnl-2021-BCS.175}

Introduction Infective endocarditis is a complex area of cardiology, with a highly variable clinical history and frequent atypical presentations. Despite advances in management it remains associated with a high mortality and severe complications. Most patients are diagnosed and managed outside cardiothoracic centres, either for medical management only, or prior to surgical treatment. These patients may still benefit from a coordinated approach to their care, and early input from a surgical team.ESC guidelines recommend the formation of an endocarditis team in reference centres to manage complex cases and advise on non-complicated cases in other centres. This multidisciplinary approach has been shown to significantly reduce 1 year mortality. We created an endocarditis team within a non-surgical centre, with remote input from a Cardiothoracic Surgeon, to aim to improve levels of patient care and outcomes.

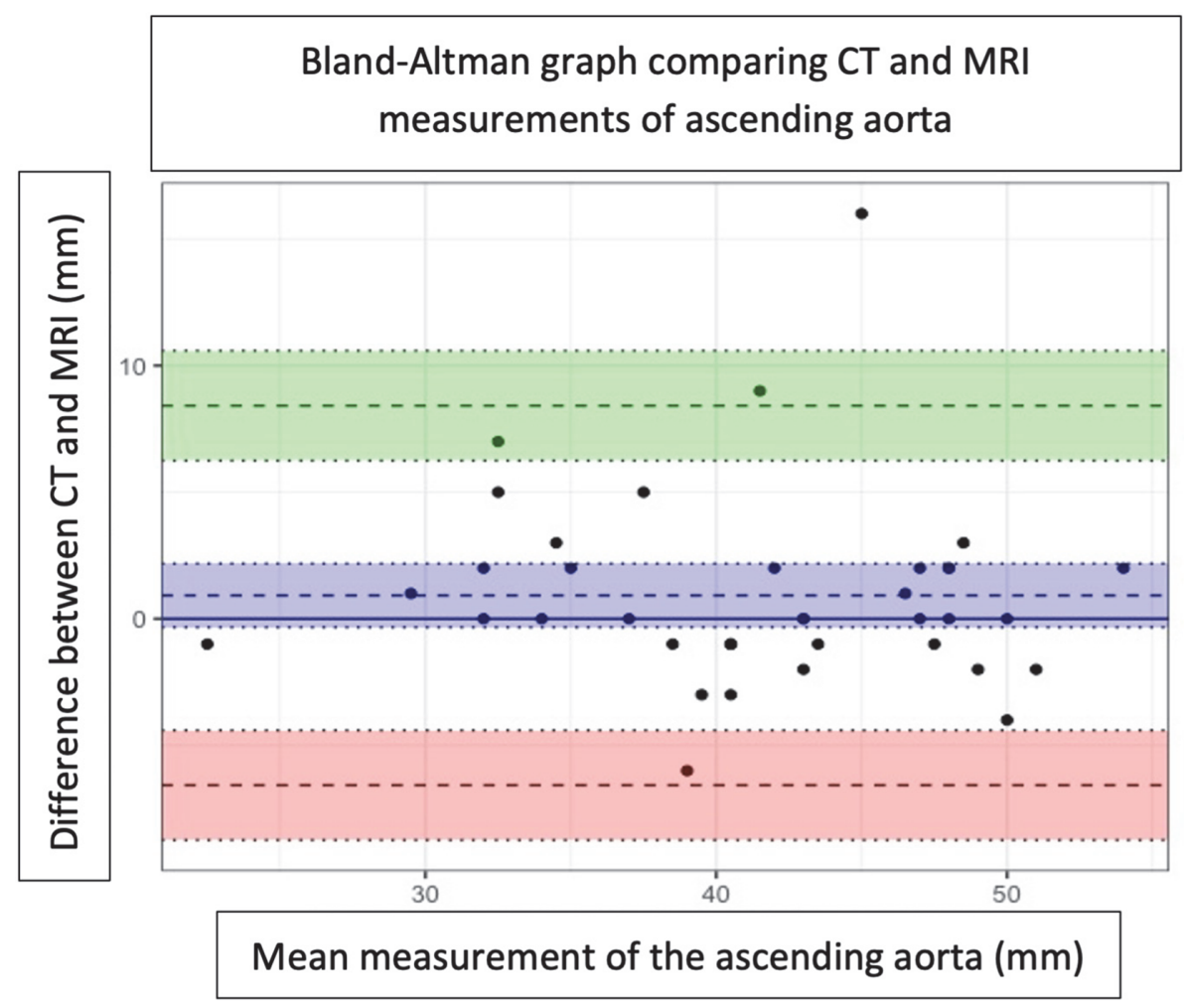

Abstract 177 Figure 1 
Methods A weekly multidisciplinary meeting (MDM) for review of patients with presumed endocarditis was created. Attendees were invited from cardiology, microbiology, elderly care and acute medicine, with cardiothoracic input from the regional surgical centre. Meetings were held via Microsoft Teams to allow input between the hospital sites involved. Imaging studies could be viewed by all. Attendance was open to the cardiology directorate including junior doctors, cardiac physiologists and nurses for on-going education and multidisciplinary input.

An electronic referral form ensured documentation of patient history, Duke score, imaging and microbiology investigations and current treatment. This was updated weekly with outcomes and recommendations from the MDM and appeared on the electronic patient record.

After 3 months, a questionnaire was circulated to assess attendees' feelings about the meeting and areas for improvement.

Results Over 3 months, 16 patients were referred to the meeting for review. Eleven were treated as endocarditis; after review the remaining 5 were felt to have an alternative diagnosis. Five patients were transferred for surgery or device explant. Others were either not suitable for surgical intervention or did not require surgery. In 11 (68\%) cases the MDM added to the patient management plan or changed diagnosis. Meetings had an average of 18 attendees across specialties and grades (figure 1). The majority felt very satisfied with the workings of the MDM (figure 2). Positive aspects highlighted

\section{MDM Attendees}

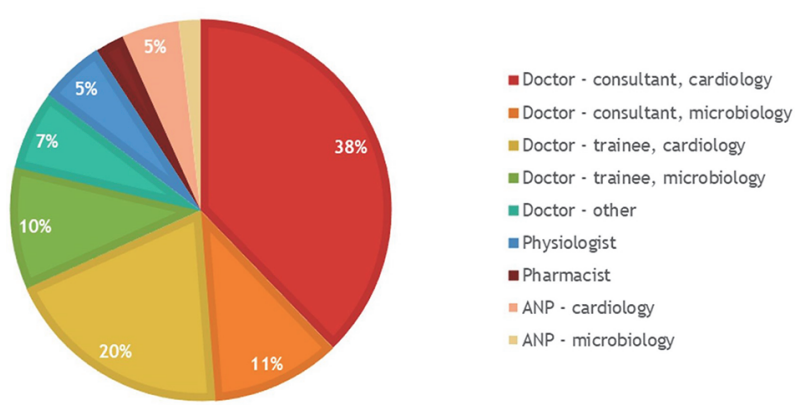

Abstract 178 Figure 1 Attendees represented the multidisciplinary nature of endocarditis care, and the opportunities for education in its management

\section{OVERALL SATISFACTION WITH MDM}

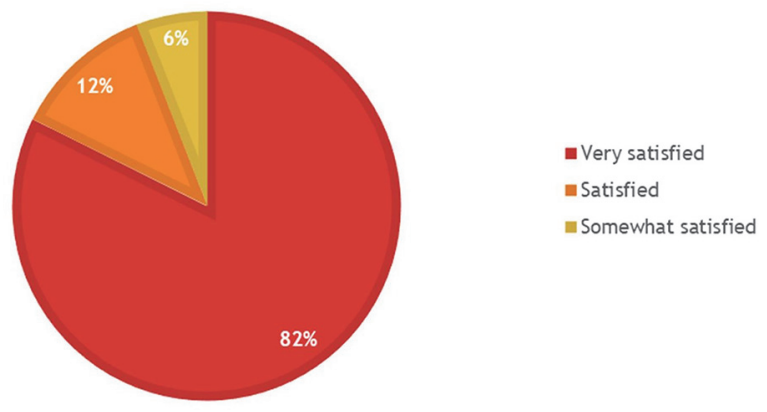

Abstract 178 Figure 2 Overall satisfacation with the MDM was high
Abstract 178 Table 1 Attendees were asked their opinions on the impact of MDM on patient

\begin{tabular}{|c|c|c|c|c|c|}
\hline $\begin{array}{l}\text { In your opinion, the MDM has } \\
\text { improved the following... }\end{array}$ & $\begin{array}{l}\text { Strongly } \\
\text { Agree }\end{array}$ & Agree & Neutral & Disagree & $\begin{array}{l}\text { Strongly } \\
\text { Disagree }\end{array}$ \\
\hline Clinical Decision Making & $12(71 \%)$ & $\begin{array}{l}5 \\
(30 \%)\end{array}$ & & & \\
\hline Co-ordinated Patient Care & $12(71 \%)$ & $\begin{array}{l}5 \\
(30 \%)\end{array}$ & & & \\
\hline $\begin{array}{l}\text { Evidence based/guideline directed } \\
\text { decision making }\end{array}$ & $11(65 \%)$ & $\begin{array}{l}5 \\
(30 \%)\end{array}$ & $1(6 \%)$ & & \\
\hline Timeliness of tests and treatments & $5(29 \%)$ & $\begin{array}{l}5 \\
(30 \%)\end{array}$ & $\begin{array}{l}6 \\
(35 \%)\end{array}$ & & \\
\hline $\begin{array}{l}\text { Overall quality of treatment } \\
\text { decisions }\end{array}$ & $11(59 \%)$ & $\begin{array}{l}6 \\
(35 \%)\end{array}$ & & & \\
\hline Knowledge of imaging findings & $10(59 \%)$ & $\begin{array}{l}5 \\
(30 \%)\end{array}$ & $1(6 \%)$ & & \\
\hline $\begin{array}{l}\text { Knowledge of antimicrobial } \\
\text { findings }\end{array}$ & $10(59 \%)$ & $\begin{array}{l}6 \\
(35 \%)\end{array}$ & $1(6 \%)$ & & \\
\hline $\begin{array}{l}\text { Knowledge of need for surgical } \\
\text { intervention }\end{array}$ & $12(71 \%)$ & $\begin{array}{l}3 \\
(18 \%)\end{array}$ & $\begin{array}{l}2 \\
(12 \%)\end{array}$ & & \\
\hline $\begin{array}{l}\text { Confidence in individual IE patient } \\
\text { management }\end{array}$ & $11(65 \%)$ & $\begin{array}{l}5 \\
(30 \%)\end{array}$ & $1(6 \%)$ & & \\
\hline
\end{tabular}

included the multidisciplinary input and educational aspects of the MDM. The meeting was felt to improve knowledge of, and confidence in, management of the condition (table 1). Comments for changes or improvements were predominantly related to time (2) and duration (3) of the meeting.

Conclusion We have successfully introduced an effective, wellattended, weekly MDM for the management of endocarditis, resulting in increased confidence in patient management, and the ability to coordinate investigation and on-going care for these patients.

Conflict of Interest na

\section{CT-VISIBLE MICROSPHERES ENABLE IN VIVO TRACKING OF BIOMATERIAL DISTRIBUTION AFTER ULTRASOUND- GUIDED INTRAMYOCARDIAL INJECTION}

Annalisa Bettini, P. Stephen Patrick, Richard Day, Daniel Stuckey. University College London, London, UK

\subsection{6/heartjnl-2021-BCS.176}

Efficacy of cell therapies are often diminished by low cell retention. A method to visualise the location of grafted cells and biomaterials after delivery could be used to optimise therapies by verifying injection success, retention of the therapeutic and distribution of the product. To address these challenges an injectable cell-substrate consisting of highly porous microspheres containing the computed tomography (CT) contrast agent barium sulphate (BaSO4) was developed.Porous microspheres $(<250 \mu \mathrm{m})$ were fabricated via Thermally Induced Phase Separation (TIPS) using a 2\% (w/v) 75:25 poly (DL-lactide-co-glycolide) polymer solution containing a $20 \%$ $(\mathrm{w} / \mathrm{v})$ colloidal suspension of particulate $\mathrm{BaSO} 4$. Culture media conditioned with BaSO4-loaded microspheres $(46.87 \mathrm{mg} / \mathrm{ml}$ ) showed no significant toxicity when cultured with L929 fibroblasts for up to 7 days (maximum toxicity $12 \%$ vs $5 \%$ matched control media, $\mathrm{n}=4, \mathrm{p}<0.01)$. Suspensions of BaSO4- 